\title{
NIR-laser-triggered gadolinium-doped carbon dots for magnetic resonance imaging, drug delivery and combined photothermal chemotherapy for triple negative breast cancer
}


Renjun Pei ${ }^{3^{*}}$, Xing Chen ${ }^{1 *}$ (D) and Gang Huang ${ }^{2^{*}}$

\begin{abstract}
Background: Owing to high genetic diversities of tumor cells and low response rate of standard chemotherapy, patients with triple negative breast cancer (TNBC) have short progression-free survivals and poor outcomes, which need to explore an effective approach to improve therapeutic efficacy.

Methods: Novel gadolinium doped carbon dots (Gd@CDs) have been designed and prepared through hydrothermal method with 3,4-dihydroxyhydrocinnamic acid, 2,2'-(ethylenedioxy)bis(ethylamine) and gadolinium chloride. The synthesized nanostructures were characterized. Taking advantage of good biocompatibility of Gd@CDs, a nanoplatform based on Gd@CDs has been developed to co-deliver chemotherapy drug doxorubicin hydrochloride (Dox) and a near-infrared (NIR) photothermal agent, IR825 for magnetic resonance imaging (MRI) guided photothermal chemotherapy for TNBC.

Results: The as-synthesized Dox@IR825@Gd@CDs displayed favorable MRI ability in vivo. Upon NIR laser irradiation, Dox@IR825@Gd@CDs could convert the NIR light to heat and efficiently inhibit tumor growth through photothermal chemotherapy in vitro and in vivo. Additionally, the impact of photothermal chemotherapy on the murine motor coordination was assessed by rotarod test.Dox@IR825@Gd@CDs presented low toxicity and high photothermal chemotherapy efficiency.

Conclusion: A noble theranostic nanoplatform (Dox@IR825@Gd@CDs) was developed that could be tailored to achieve loading of Dox and IR825, intracellular delivery, favorable MRI, excellent combination therapy with photothermal therapy and chemotherapy to enhance therapeutic effect against TNBC cells. This study will provide a promising strategy for the development of Gd-based nanomaterials for MRI and combinational therapy for TNBC.
\end{abstract}

Keywords: Carbon dots, Magnetic resonance imaging, Photothermal chemotherapy, Drug delivery, Triple negative breast cancer therapy

\footnotetext{
*Correspondence: dongpinghuang@gxmu.edu.cn; rjpei2011@sinano.ac.cn; chenx63@163.com; wangyi.07@163.com

${ }^{\dagger}$ Qunjiao Jiang and Li Liu contributed equally to this work

1 School of Public Health, Guangxi Medical University, Nanning 530000,

China

2 State Key Laboratory of Non-Food Biomass and Enzyme Technology, Guangxi Academy of Sciences, Nanning 530007, China

${ }^{3}$ Key Laboratory of Nano-Bio Interface, Suzhou Institute of Nano-Tech

and Nano-Bionics, Chinese Academy of Sciences, Suzhou 215123, China
}

(c) The Author(s) 2021. This article is licensed under a Creative Commons Attribution 4.0 International License, which permits use, sharing, adaptation, distribution and reproduction in any medium or format, as long as you give appropriate credit to the original author(s) and the source, provide a link to the Creative Commons licence, and indicate if changes were made. The images or other third party material in this article are included in the article's Creative Commons licence, unless indicated otherwise in a credit line to the material. If material is not included in the article's Creative Commons licence and your intended use is not permitted by statutory regulation or exceeds the permitted use, you will need to obtain permission directly from the copyright holder. To view a copy of this licence, visit http://creativeco mmons.org/licenses/by/4.0/. The Creative Commons Public Domain Dedication waiver (http://creativecommons.org/publicdomain/ zero/1.0/) applies to the data made available in this article, unless otherwise stated in a credit line to the data. 


\section{Background}

The imaging-guided theranostics for the diagnosis and treatment of cancer, which seeks to address traditional medical challenges including poor bioavailability, systemic toxicity and low efficiency, now encompasses wider areas of cancer therapy [1-3]. An ideal therapeutic platform should possess the capability to locate tumors, achieve deep penetration, guide cancer therapy and improve therapeutic effect $[1,2]$. Magnetic resonance imaging (MRI) is regarded as one of most powerful noninvasive techniques for true $3 \mathrm{D}$ and high quality multiplanar image of soft tissue in vivo $[4,5]$. Gadolinium (Gd), possessing unpaired electrons in its outermost shell, not only creates strong local proton environment but also contributes to the overall signal intensity of $\mathrm{T}_{1}$-weighted images [6]. Although $\mathrm{Gd}^{3+}$-based contrast probes, such as Gd-DTPA and Gd-DOTA, have play a crucial part in clinical MRI, the sensitivity of these contrast agents for distinguishing the tumors from the other surrounding organs still remains to be enhanced [5]. Moreover, since free $\mathrm{Gd}^{3+}$ ions are toxic in vivo, the potential Gd retention within the skin, bones, and solid organs may cause a high toxicity profile by calcium antagonist, nephrogenic systemic fibrosis (NSF) in patients with impaired renal function [7-10]. To address these questions, new generation of Gd-containing nanoprobes, including $\mathrm{Gd}_{2} \mathrm{O}_{3}$ nanoparticles, $\mathrm{Gd}$-loaded silica nanoparticles, Gd-doped $\mathrm{Fe}_{3} \mathrm{O}_{4}$ nanoparticles and Gd-encapsulated carbon dots (CDs), have been developed to suppress the side-effect caused by the Gd leakage [11]. Among these nanoparticles, CDs have shown remarkable physicochemical and biological properties, such as simple preparation, unique nanostructures, ease of functionalization, good photostability, low toxicity, excellent biocompatibility and cell membrane permeability $[12,13]$. Therefore, Gd-encapsulated CDs have been recognized as smart candidates as MRI probes and drug carriers for cancer therapy.

Triple negative breast cancer (TNBC) lacks estrogen receptor, progesterone receptor and human epidermal growth factor receptor [14], leading to high heterogeneity, extremely aggressive tumor biology and a low prognosis [15]. Although some TNBC patients are sensitive to anthracyclines and taxanes, long-term chemotherapy evolves drug resistance, resulting in poor overall survivals $[16,17]$. To deal with these drawbacks, synergistic approach involving two or more therapeutic modalities can enhance therapeutic efficacy, because single chemotherapy could not get rid of all the cancer cells, and might increase the risk of the recurrence or metastasis [18-21]. In addition to conventional chemotherapy, photothermal therapy (PTT), as a minimally invasive and highly effective cancer treatment method, could effectively convert the photo energy into heat to kill cancer cells under light irradiation, increase cell membrane permeability to improve the uptake of drug, and further enhance the effectiveness of chemotherapy [2123]. Photothermal chemotherapy could be recognized as one of the most effective combinatorial treatments to synergistically destroy tumors while preventing recurrence and metastasis [24-26]. Hence, an ideal therapeutic platform combined photothermal chemotherapy need to explore to improve therapeutic efficacy against TNBC.

In this work, Gd-encapsulated carbon dots (Gd@CDs) were synthesized through a hydrothermal method with 3,4-dihydroxyhydrocinnamic acid, 2,2'-(ethylenedioxy) bis(ethylamine) and gadolinium chloride. A nanoplatform Dox@IR825@Gd@CDs has been developed by delivering chemotherapy drug Dox and photothermal agent IR825 for MRI guided combination photothermal chemotherapy for TNBC (Scheme 1). This study will provide a promising strategy for the development of Gdbased nanomaterials for MRI and combinational therapy of TNBC.

\section{Materials and methods \\ Materials}

3,4-dihydroxyhydrocinnamic acid (DHCA), 2,2'-(ethylenedioxy)bis(ethylamine) (EDA), anhydrous gadolinium chloride $\left(\mathrm{GdCl}_{3}\right)$, doxorubicin hydrochloride (Dox), 1,1-diphenyl-2-picrylhydrazyl (DPPH) and other chemical reagents were bought from Energy Chemical Co. Ltd without further purification. Fetal bovine serum (FBS), trypsin, penicillin and streptomycin were obtained from Biological Industries (Kibbutz Beit Haemek, Israel). RPMI Medium 1640 basic $(1 \times)$ was purchased from Thermo Fisher Biochemical Products co. LTD (Beijing, China). Cell Counting Kit-8 (CCK-8) was bought from Dojindo Chemical technology co. LTD (Shanghai, China). The murine breast cancer 4T1 cell line and human breast cancer MDA-MB-231 cell line were obtained from Cell Bank of Chinese Academy of Sciences.

\section{Preparation of Gd@CDs}

$369.5 \mathrm{mg}$ of DHCA, $0.584 \mathrm{~mL}$ of EDA, $78 \mathrm{mg}$ of $\mathrm{GdCl}_{3}$ and $20 \mathrm{~mL}$ of deionized water were added into an autoclave and heated to $200{ }^{\circ} \mathrm{C}$ for $5 \mathrm{~h}$. After cooling to room temperature, the mixture was centrifuged at $6000 \mathrm{rpm}$ for $10 \mathrm{~min}$ to remove brown particles. The supernatant solution was filtered three times through a $0.22 \mu \mathrm{m}$ membrane to remove large particles, and then transferred into a dialysis membrane $(\mathrm{MWCO}=500)$ for dialysis against deionized water for 72 h. Gd@CDs were collected and lyophilized for further characterization. 


\section{Characterization of Gd@CDs}

Nuclear magnetic resonance (NMR) spectra were recorded in $\mathrm{D}_{2} \mathrm{O}$ on Agilent Technologies 800/54 premium. Fourier transform infrared spectroscopy (FT-IR) was performed on Thermo Scientific Nicolet iS10 spectrometer. UV-vis absorption spectra were collected on Agilent Cary 60 spectrophotometer and Shimadzu UV-1900 spectrophotometer. The fluorescence spectra were measured on Hitachi F-7000. The fluorescence lifetime and quantum yield were recorded on an Edinburgh Instruments FLS980. Gadolinium in Gd@CDs was quantified by Thermo Fisher iCAP Qnova Series inductively coupled plasma mass spectrometry (ICP-MS). X-ray photoelectron spectroscopy (XPS) analysis was recorded by Kratos Axis Utra Dld. Raman spectra were measured on Labram Aramis with an excitation wavelength of $532 \mathrm{~nm}$. The morphologies were observed with FEI Tecnai G2 F30 S-TWIN TEM. The hydrodynamic diameter and zeta potential of nanoparticles were measured by a PSS-Nicomp 380ZLS.

\section{Biocompability of Gd@CDs}

Cellular viability assays. $293 \mathrm{~T}$ cells were incubated with standard DMEM culture medium with $10 \%$ FBS and $1 \%$ penicillin/streptomycin at $37{ }^{\circ} \mathrm{C}$ under $5 \% \mathrm{CO}_{2}$ atmosphere. $293 \mathrm{~T}$ cells $\left(1 \times 10^{4}\right.$ cells per well $)$ were seeded onto 96-well plate until adherent and then treated with different concentrations of Gd@CDs $(0.1,0.2,0.5$, $1.0 \mathrm{mg} / \mathrm{mL}$ ), while PBS was used as control. After then, $293 \mathrm{~T}$ cells were incubated for $24 \mathrm{~h}$. The absorbance at $450 \mathrm{~nm}$ was recorded by Thermo Fisher multiskan Go spectrophotometer. Then, the viability of cells was calculated according to Eq. (1):

$$
\operatorname{Viability}(\%)=\frac{A_{s}-A_{b}}{A_{c}-A_{b}} \times 100
$$

$A_{s}, A_{b}, A_{c}$ were the absorbance of sample, blank and control groups, respectively. Three replicates were carried out.

Toxicity study in vivo. Kunming mice $(\mathrm{n}=18$, female, 5 weeks) were purchased from Guangxi Medical University Laboratory Animal Center and used under protocols approved by Guangxi Medical University Laboratory Animal Center. Kunming mice were randomly divided into 3 groups. The mice were injected via tail vein every three days $(0,3,6,9,12,15$ Day) and treated as follows: (a) saline (100 $\mu \mathrm{L}),($ b) Gd@CDs $(0.3 \mathrm{mg} / \mathrm{kg}),(\mathrm{c}) \mathrm{Gd} @$ CDs $(3 \mathrm{mg} / \mathrm{kg})$. The body weight changes of the injected mice were monitored. The mice were sacrificed at $16 \mathrm{~d}$ to collect blood for blood biochemical assay. In addition, the heart, liver, spleen, lung and kidney of mice were gathered and weighted. All tissues were stained with $H E E$ staining. However, the Balb/c mice were sacrificed

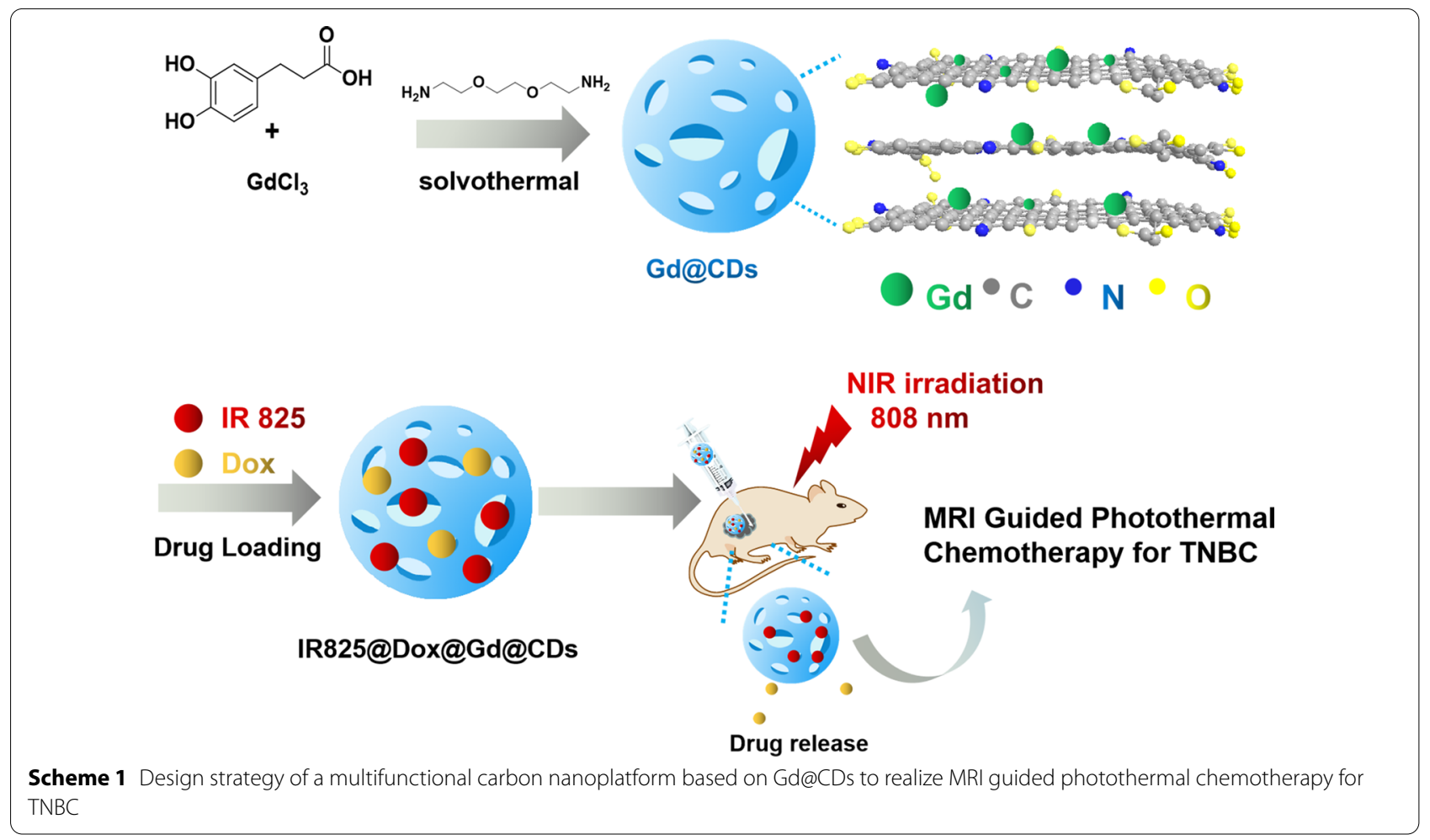


after $24 \mathrm{~h}$ post injection for histopathology examination: (a) saline, (b) Gd@CDs (0.1 mg/kg), (c) Gd@CDs (1 mg/ kg), (d) Gd@CDs (10 mg/kg).

\section{Synthesis of Dox@IR825@Gd@CDs}

Gd@CDs (40 mg) were dispersed in deionized water. Then $0.2 \mathrm{~mL}$ of DMSO solution containing $4 \mathrm{mg}$ of Dox and $4 \mathrm{mg}$ of IR825 was dropwise added. The mixture was incubated at $37^{\circ} \mathrm{C}$ on a shaker for $24 \mathrm{~h}$, yielding Dox@ IR825@Gd@CDs solution, which was purified by dialysis against water for $24 \mathrm{~h}$ before lyophilization. Drug loading efficiency and encapsulation were calculated according to Eqs. (2), (3).

\section{Cellular uptake}

4T1 cells were incubated with standard RPMI-1640 culture medium with $10 \% \mathrm{FBS}$ and $1 \%$ penicillin/streptomycin at $37{ }^{\circ} \mathrm{C}$ under $5 \% \mathrm{CO}_{2}$ atmosphere. $4 \mathrm{~T} 1$ cells were seeded on glass coverslips $\left(10^{5}\right.$ cells per slip) until adherent and incubated with Dox@IR825@Gd@CDs (0.5 mg/ $\mathrm{mL}$ ) for $4 \mathrm{~h}$. After being washed three times with PBS to remove the excess nanoparticles, the cells were fixed by $4 \%$ paraformaldehyde and washed again with PBS. The cells were washed with PBS containing $0.2 \%$ Triton-100 for easy permeability. Afterwards, the cells were stained with DAPI and imaged by EVOS FL Auto. Three replicates were carried out.

$$
\begin{aligned}
& \text { Drug loading efficiency }(\%)=\frac{\text { mass of the encapsulated drug }}{\text { total mass of the sample }} \times 100 \\
& \text { Drug encapsulation efficiency }(\%)=\frac{\text { mass of the encapsulated drug }}{\text { mass of the initial drug }} \times 100
\end{aligned}
$$

The hydrodynamic diameters of Dox@IR825@Gd@ CDs in the presence of PBS with 10\% FBS were recorded on a PSS-Nicomp 380ZLS during $99 \mathrm{~h}$.

\section{Drug release in vitro}

Dox@IR825@Gd@CDs dialysate (2 mL) was transferred into new dialysis membrane $(\mathrm{MWCO}=3500 \mathrm{D})$ and immersed in $25 \mathrm{~mL}$ of PBS buffer at $\mathrm{pH} 4.92$ or 7.38 for 120 h. $4 \mathrm{~mL}$ of medium outside the dialysis membrane was taken out and an equal volume of fresh PBS was replenished at desired time points. The release behaviors of Dox and IR825 were investigated using a dialysis membrane and the absorbance was measured at $530 \mathrm{~nm}$ and $790 \mathrm{~nm}$, respectively. Three replicates were carried out.

\section{Photothermal effect evaluations}

Dox@IR825@Gd@CDs solutions (0.1, 0.2, 0.5, 1.0 mg/ $\mathrm{mL}$ ) were exposed to an $808 \mathrm{~nm}$ laser irradiation (3.0 W) for $5 \mathrm{~min}$. Solution temperatures were recorded by thermometer and thermal imaging system (Fluke Ti450) at an interval time to evaluate the photothermal property of Dox@IR825@Gd@CDs. Three replicates were carried out. Additionally, to evaluate photothermal stability, Dox@IR825@Gd@CDs (1 mg/mL) solution was irradiated with an $808 \mathrm{~nm}$ laser $(3.0 \mathrm{~W})$ for $5 \mathrm{~min}$ and then naturally cooled down to room temperature. The temperature changes were monitored with a time intervals of 1 min during 5 cycles of laser on / off irradiation.

\section{Combined photothermal chemotherapy in vitro}

The cellular viability was assessed against 4T1 cells and MDA-MB-231 cells by a CCK-8 assay. MDA-MB-231 cells were incubated with standard RPMI-1640 culture medium with $10 \% \mathrm{FBS}$ and $1 \%$ penicillin/streptomycin at $37{ }^{\circ} \mathrm{C}$ under $5 \% \mathrm{CO}_{2}$ atmosphere. $4 \mathrm{~T} 1$ cells $\left(5 \times 10^{3}\right.$ cells per well) and MDA-MB-231 cells $\left(1 \times 10^{4}\right.$ cells per well) were seeded onto 96-well plate until adherent and then treated with different concentrations of Gd@CDs, IR825@Gd@CDs and Dox@IR825@Gd@CDs (0.1, 0.2, $0.5,1.0 \mathrm{mg} / \mathrm{mL})$, while PBS was used as control. IR825@ Gd@CDs groups were irradiated with a laser (808 nm, $3 \mathrm{~W})$ for 5 min. Dox@IR825@Gd@CDs groups were treated in the absence or presence of a laser irradiation $(808 \mathrm{~nm}, 3 \mathrm{~W})$ for $5 \mathrm{~min}$. After then, the cells were further incubated for $12 \mathrm{~h}$. The viability was examined by CCK-8 assay. The absorbance at $450 \mathrm{~nm}$ was recorded by Thermo Fisher multiskan Go spectrophotometer. The viability of cells was calculated according to Eq. (1). Three replicates were carried out.

Calcein-AM/PI assay against $4 \mathrm{~T} 1$ cells and MDAMB-231 cells were also performed to evaluate the antitumor efficiency in vitro. Cells $\left(5 \times 10^{4}\right.$ cells per well) were seeded onto 24-well plate and treated by incubation of different formulations (Gd@CDs, IR825@Gd@ CDs, Dox@IR825@Gd@CDs, 0.5 mg/mL) with/without irradiation in a similar way as the cellular viability assays, described above. The resultant cells were co-stained with calcein-AM and PI, and imaged by EVOS FL Auto. Three replicates were carried out. 


\section{$M R I$ in vitro and in vivo}

MRI in vitro was acquired from a $1.5 \mathrm{~T}$ Philip MRI instrument under following parameters: TR/TE $=3500 / 20 \mathrm{~ms}$, $\mathrm{NSA}=1, \mathrm{FOV}=60 \times 60 \mathrm{~mm}^{2}$, matrix size $=256 \times 256$, section thickness $=1 \mathrm{~mm}$. A series of diluted Gd@CDs solution were imaged comparing to commercial contrast agent gadopentetate dimeglumine (Gd-DTPA) with the same concentrations of Gd.

MRI in vivo was collected using a $1.5 \mathrm{~T}$ scanner (HT-MRSI60-35A, Shanghai Huantong Science and Education Equipment Co., Ltd). The parameters for T1 imaging were set as follows: TR/TE $=100 / 14.12 \mathrm{~ms}$, matrix $=512 \times 256, \quad$ FOV $=80 \times 45 \mathrm{~mm}^{2}$, slice thickness $=0.3 \mathrm{~mm}, 128$ slices and no gap between slices. Female BALB/c mice ( 4 weeks old) were obtained from Changzhou Cavens Laboratory Animal Co., Ltd. and acclimated for 2 weeks before use. To fabricate a xenograft tumor model, the armpit of mice was subcutaneously injected with $2 \times 10^{6} 4 \mathrm{~T} 1$ cells suspended in 100 $\mu \mathrm{L}$ of PBS. When the tumor size reached about $10 \mathrm{~mm}$ in diameter after about 2 weeks, the mice were used for MRI experiments. The tumor-bearing mice were injected intravenously $(\mathrm{n}=2)$ or in situ $(\mathrm{n}=2)$ with Dox@IR825@ Gd@CDs. MR images were acquired at 0, 1, 2, 3, 4, 5, 6 and $12 \mathrm{~h}$ after intravenous injection and at $10 \mathrm{~min}$ after in situ injection.

\section{Combined photothermal chemotherapy in vivo}

Animal Model: nude mice $(\approx 16 \mathrm{~g}$, female, 5 weeks $)$ were purchased from Guangxi Medical University Laboratory Animal Center and were randomly divided into 4 groups. For the $4 \mathrm{~T} 1$ murine breast tumor model, 4T1 cells $\left(4 \times 10^{5}\right)$ were subcutaneously injected. The mice were used when their tumor volumes approached 10 $\mathrm{mm}^{3}$. The tumor-bearing mice were injected the sample solution $(20 \mu \mathrm{L}, 8 \mathrm{mg})$ in situ and treated as follows: (a) saline ( $\mathrm{n}=5),(\mathrm{b})$ Dox@IR825@Gd@CDs $(\mathrm{n}=5),(\mathrm{c})$ IR825@Gd@CDs (808 nm laser, 1.5 W, $10 \mathrm{~min}, \mathrm{n}=5$ ), (d) Dox@IR825@Gd@CDs (808 nm laser, 1.5 W, 10 min, $\mathrm{n}=5$ ). The thermal images of the mice were observed by Fluke thermal imaging after treatment. Tumor size and body weight were also recorded. Tumor volume $(V)$ was calculated by the following equation: $V=a b^{2} / 2$ ( $a$ and $b$ denoted the length and width of tumor). The heart, liver, spleen, lung, kidney and tumor of mice were gathered and weighted after 14 days treatments. All tissues were stained with $H \mathcal{E} E$ staining.

\section{Biodistribution of Dox@IR825@Gd@CDs}

To evaluate the biodistribution of Dox@IR825@Gd@ CDs in vivo, the tumor-bearing mice were sacrificed after $24 \mathrm{~h}$ post-treatment $(\mathrm{n}=4)$. The heart, liver, spleen, lung, kidney and tumor were weighted and predigested with $5 \mathrm{~mL}$ of $\mathrm{HNO}_{3}$ by microwave digestion (CEM MARS6 CLASSIC). The gadolinium contents were measured by ICP-MS.

\section{Rotarod test}

To evaluate the impact of combination therapy on murine motor coordination, the nude mice, tumor-bearing mice before and after 14 days treatments were assessd by rotarod test. The initial roating speed was set at $5 \mathrm{rpm}$ for $10 \mathrm{~s}$, then uniformly increased to $25 \mathrm{rpm}$ within $1 \mathrm{~min}$. The duration was automatically recorded by Ugo Basile 47,650 RotaRod.

\section{Statistical analysis}

The data were expressed as mean \pm standard deviation (SD). Results of biochemistryanalysis, mouse weight, tumor weight, temperature increments of various amount of Dox@IR825@Gd@CDs suspension under NIR laser irradiation, tumor volume assays and rotarod test were performed using multiple comparisons in analysis of variance (ANOVA). Comparison of the release rate of Dox and IR825 in different $\mathrm{pH}$ solutions and temperature increments of Dox@IR825@ Gd@CDs suspension under NIR laser irradiation for five cycles have been made with $\mathrm{t}$ test. $P$ values less than 0.05 were defined as statistically significant.

\section{Live subject statement}

All experiments were approved by the Ethics Committee of Guangxi Medical University and carried on in strict compliance with the relevant laws and institutional guidelines of Guangxi Medical University, Nanning, China (20140307A, 20140307B).

\section{Results and discussion}

\section{Preparation and characterization of Gd@CDs}

Gd@CDs were prepared via the typical solvent-thermal method, in which DHCA and anhydrous $\mathrm{GdCl}_{3}$ were used as the carbon source and MRI contrast agent, while EDA was as a passivation agent. Gd@CDs were purified by filtration and dialysis to remove nanoparticles aggregations and unreacted precursors. Then, Gd@CDs were further characterized.

Comparing with the ${ }^{1} \mathrm{H}$ NMR spectra of EDA and DHCA, the chemical shifts of Gd@CDs at 1.39-4.39 ppm were assigned to the protons on saturated carbons and the appearing signals in the range of 6.24 and $7.03 \mathrm{ppm}$ were attributed to the protons on the amine groups (Fig. 1a). The chemical shifts at $8.23 \mathrm{ppm}$ revealed the protons on the aromatic ring. In the ${ }^{13} \mathrm{C} N M R$ 
spectrum of Gd@CDs (Fig. 1b), three sharp characteristic peaks appeared in the chemical shifts of 38.95, 66.42 and $69.40 \mathrm{ppm}$, which were attributed to the carbon atoms: $-\mathrm{O}-\mathrm{CH}_{2} \underline{\mathrm{CH}_{2}}-\mathrm{NH}_{2},-\mathrm{O}-\mathrm{CH}_{2} \underline{\mathrm{C}} \mathrm{H}_{2}-\mathrm{O}-$, and $-\mathrm{O}-\mathrm{CH}_{2} \mathrm{CH}_{2}-\mathrm{NH}_{2}$. Other weak characteristic peaks were roughly divided into two regions: the saturated carbon atoms in the region of 22.9-69.34 ppm, and the unsaturated carbon atoms region $(\mathrm{C}=\mathrm{C})$, aromatic with carbon-carbon double bond at 115.94-143.89 ppm and carbon-oxygen double bond at 170.64-196.84 ppm [27].

In FT-IR spectra (Fig. 1c), a very broad peak from 3700 to $3000 \mathrm{~cm}^{-1}$ indicated the presence of unsaturation hydrogen $(=\mathrm{C}-\mathrm{H})$ stretches and exchangeable protons, typically from hydroxyl groups, amide groups or carboxylic acid groups [28]. The peaks of 2917 and $2872 \mathrm{~cm}^{-1}$ were attributed to $\mathrm{C}-\mathrm{H}$ stretches of alkyl groups [28]. The signals at $1551 \mathrm{~cm}^{-1}$ belonged to alkene stretches $[29,30]$. The intense IR absorptions at $1391 \mathrm{~cm}^{-1}$ and $1099 \mathrm{~cm}^{-1}$ were attributed to $\mathrm{C}-\mathrm{O}$ and $\mathrm{C}-\mathrm{N}$ stretches (Fig. 1c) [29, 30]. As shown in Raman spectrum (Fig. 1d), the peaks of $1445 \mathrm{~cm}^{-1}$ and $1651 \mathrm{~cm}^{-1}$ belonged to $\mathrm{D}$ band ( $\mathrm{sp}^{3}$ hybridization) and $\mathrm{G}$ band $\left(\mathrm{sp}^{2}\right.$ hybridization), respectively [31]. The integrated intensity ratio of $\mathrm{D}$ and $\mathrm{G}$ bands $\left(I_{\mathrm{D}} / I_{\mathrm{G}}=0.54\right)$ was directly proportional to the surface defect density of carbon points, indicating a high degree of graphitization on the surface of Gd@ CDs [30, 32]. For the XRD pattern (Fig. 2a), a weak diffraction peak at $22.58^{\circ}$ was due to the amorphous carbon structure, similar to graphene lamellar structure [30, 33, 34]. The morphologies of Gd@CDs were observed by the HRTEM images (Fig. 2b), exhibiting the spherical shape with an average diameter of $2.58 \mathrm{~nm}$ and a lattice fringe distance of $0.16 \mathrm{~nm}$. Gd@CDs exhibited a zeta potential of $-16.31 \mathrm{mV}$ and a size of $308.8 \mathrm{~nm}$ by dynamic light scattering (DLS) (Additional file 1: Figure S1a). However, the size of Gd@CDs by the HRTEM images was much smaller than that of DLS result. The dry particles were observed in HRTEM image, while the DLS measured the hydrodynamic size of nanoparticles in suspension, both core and surrounding solvent layer. Furthermore, it was inevitable for Gd@CDs to aggregate due to low surface charge and hydrogen bonds formation between $-\mathrm{NH}_{2}$ and $-\mathrm{COOH}$ which Gd@CDs were functionalized with. Hence, the DLS results exhibited larger size than that of HRTEM images.

Gd@CDs contained C, O and N elements (Fig. 2c). The deconvoluted $\mathrm{C}$ 1s showed three peaks (Fig. 2d), including $\mathrm{C}=\mathrm{C}$ at $283.2 \mathrm{eV}, \mathrm{C}-\mathrm{C} / \mathrm{C}-\mathrm{N}$ at $284.7 \mathrm{eV}$ and $\mathrm{C}-\mathrm{O} /$
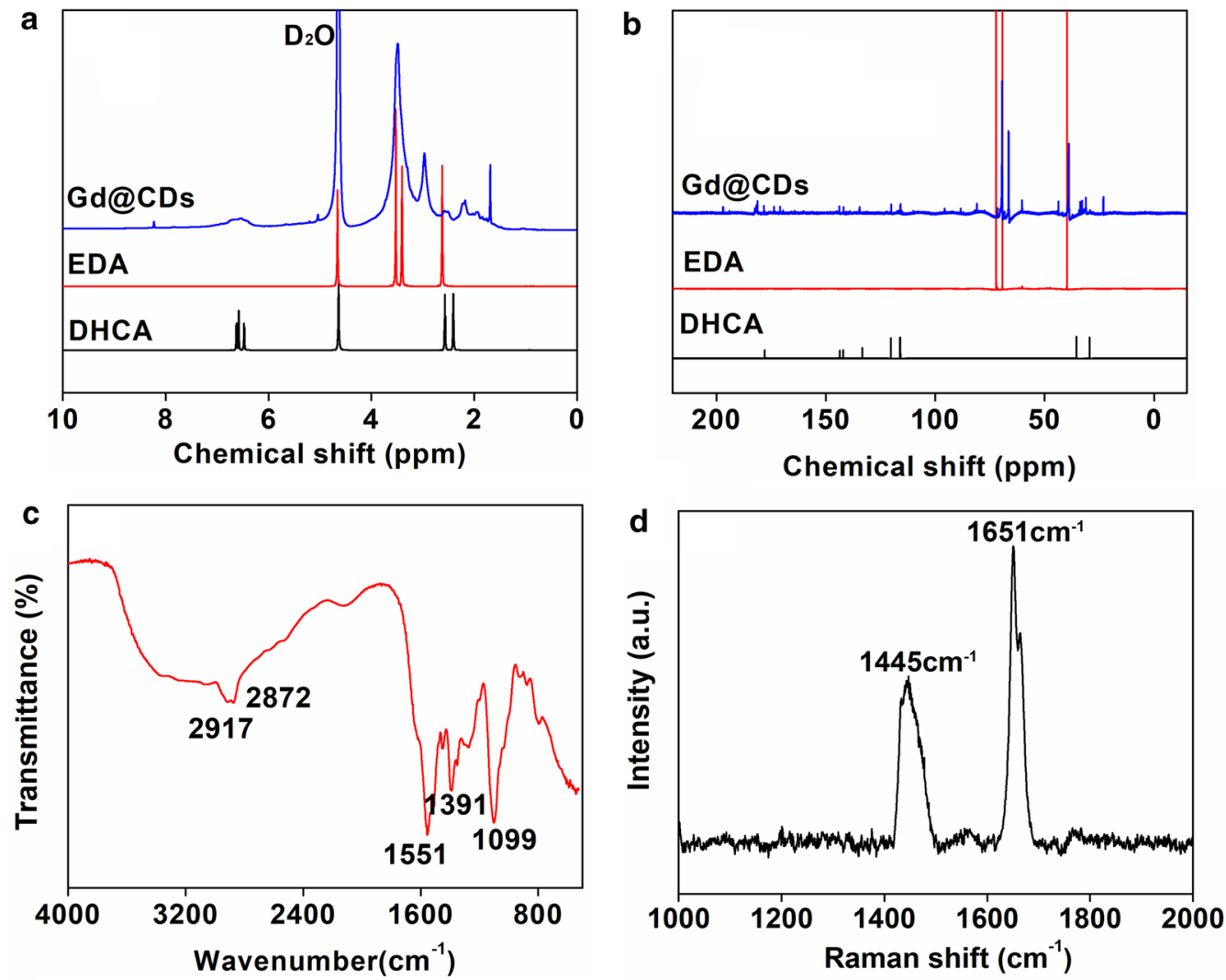

Fig. 1 a ${ }^{1}$ HNMR spectrum, b ${ }^{13}$ CNMR spectrum, c Fourier-infrared spectrum and $\mathbf{d}$ Raman spectrum of Gd@CDs 
$\mathrm{C}=\mathrm{O} / \mathrm{C}=\mathrm{N}$ at $286.2 \mathrm{eV}$ [35]. In $\mathrm{N}_{1 \mathrm{~s}}$ spectra (Fig. 2e), the signals at 398 and $399.7 \mathrm{eV}$ were attributed to $\mathrm{C}-\mathrm{N} / \mathrm{N}-$ $\mathrm{C}=\mathrm{O}$ and $-\mathrm{NH}_{2}$ [36]. The fitted $\mathrm{O}_{1 \mathrm{~s}}$ spectra gave two peaks (Fig. 2f). Peaks at 530.8 and $533.9 \mathrm{eV}$ were consistent to $\mathrm{C}=\mathrm{O}$ and $\mathrm{C}-\mathrm{O}$, demonstrating that $\mathrm{Gd} @ \mathrm{CDs}$ contained - $\mathrm{OH}$ and $-\mathrm{COOH}$ groups $[29,37]$. The concentration of Gd quantitated by ICP-MS was $0.459 \%$ in Gd@ CDs.

Gd@CDs showed a broad absorption band between 200 to $500 \mathrm{~nm}$, with two shoulders appearing at $283 \mathrm{~nm}$ and $340 \mathrm{~nm}$ (Fig. 2g). The characteristic absorption peak at $283 \mathrm{~nm}$ was attributed to the absorption peak position of the $\pi-\pi^{*}$ transition of $C=C$ skeleton on the aromatic ring. The absorption peak at $340 \mathrm{~nm}$ belonged to the $n-\pi^{*}$ transition of $\mathrm{C}=\mathrm{O}$ in the carboxyl group [29, 38]. The excitation-dependent fluorescence properties of Gd@CDs were also recorded (Fig. 2h). When the excitation wavelength was set at $360 \mathrm{~nm}, \mathrm{Gd} @ \mathrm{CDs}$ revealed a maximum emission peak at $437 \mathrm{~nm}$. Such wavelengthdependent fluorescence was also similar to conventional C-dots [39]. The fluorescence lifetime of Gd@CDs was $3.58 \mathrm{~ns}$ and the quantum yield was $26.84 \%$ (Additional file 1: Figure S1b). The fluorescence properties kept constant at different temperatures (Additional file 1: Figure
S1c) and various $\mathrm{NaCl}$ concentrations (Additional file 1: Figure S2a), and in the presence of amino acids (Additional file 1: Figure S2b). The fluorescence intensity of Gd@CDs slightly decreased at acid condition $(\mathrm{pH}<7)$ or base condition ( $\mathrm{pH}>7$, Additional file 1: Figure S2c). The maximum fluorescent quenching of Gd@CDs was occurred in presence of $\mathrm{Fe}^{3+}$ and $\mathrm{Cu}^{2+}$ (Additional file 1: Figure S2d), which could be caused by electron transfer from the negative Gd@CDs to metal ions [36, 40].Gd@ CDs held great photostability and resistance to photo bleaching upon Xe lamp illumination (Additional file 1: Figure S3a). The radical scavenging activity of Gd@CDs was assessed by DPPH method, showing that the ratio of quenching DPPH radicals improved with the increase of the concentration of Gd@CDs and the $\mathrm{EC}_{50}$ was $6.54 \mu \mathrm{g} /$ $\mathrm{mL}$, which illustrated Gd@CDs were susceptible to nitrogen radicals (Additional file 1: Figure $\mathrm{S3b}$ ).

Hemolysis assay was examined to explore the blood compatibility of Gd@CDs. No significant hemolysis phenomenon was found in different concentrations of Gd@ CDs solution, indicating Gd@CDs caused little damage to red blood cells and were biocompatible with blood (Additional file 1: Figure S4a). To explore the cytotoxicity of Gd@CDs, we first investigated Gd@CDs against
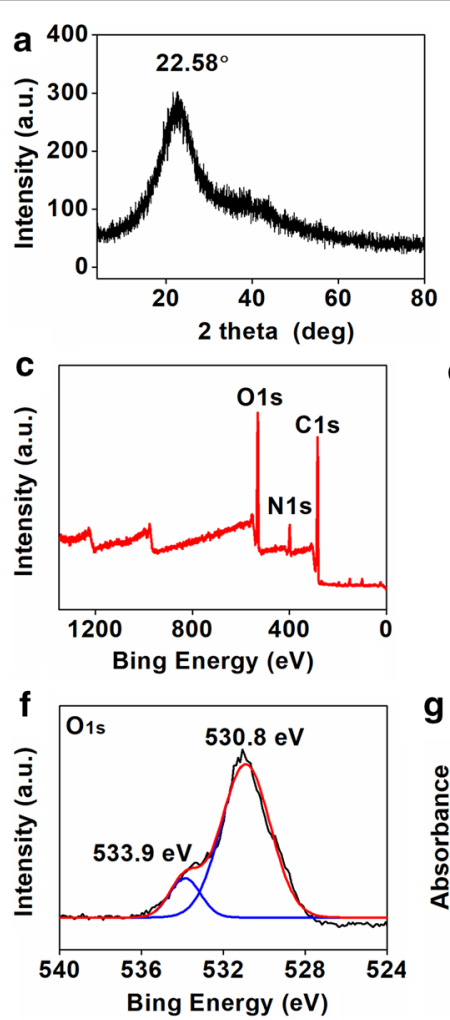

b

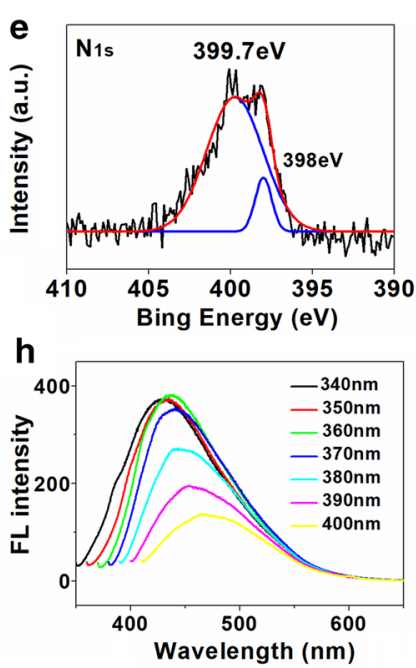

Fig. 2 Characterizations of Gd@CDs. a XRD spectrum; b HRTEM imaging (inset, statistical analysis by nanomeasurer software); c Scanned XPS spectrum, $\mathbf{d} \mathrm{C}_{1 \mathrm{~s}}$ XPS spectrum; e $\mathrm{N}_{1 \text { s }}$ XPS spectrum; $\mathbf{f} \mathrm{O}_{1 \mathrm{~s}}$ XPS spectrum; $\mathbf{g}$ The absorbance, excitation and emission spectra; $\mathbf{h}$ The emission spectra under various excitation wavelengths 
human embryonic kidneys cells (293 T cells) by CCK-8 assay (Additional file 1: Figure S4b). The cell viability was still above 90\% even when the concentration of Gd@CDs increased to $1 \mathrm{mg} / \mathrm{mL}$ after $24 \mathrm{~h}$ incubation. The results indicated the lower cytotoxicity of Gd@CDs in vitro.

In vivo histological toxicity analysis was conducted to assess cell damages of the major organs including the heart, liver, spleen, lung and kidney after $24 \mathrm{~h}$ post injection of Gd@CDs solution (Additional file 1: Figure S5). Comparing with the control groups, there were no obvious damages in the Gd@CDs treated groups, such as inflammatory response, pulmonary fibrosis, necrosis or damages in major organs.

Long term toxicity of Gd@CDs in vivo was also conducted on healthy Kunming mice model for 16 days. The mice were injected saline or Gd@CDs solution $(0.3 \mathrm{mg} /$ $\mathrm{kg}$ and $3 \mathrm{mg} / \mathrm{kg}$ ) via tail vein. The body weights of the mice were monitored during the test. There were no statistical differences in body weights at $0 \mathrm{~d}$ and $15 \mathrm{~d}$ compared with the control group (Additional file 1: Figure S6). At $16 \mathrm{~d}$, blood was collected for serum biochemistry assay. Total protein (TP), alanine aminotransferase (ALT), aspartate aminotransferase (AST), alkaline phosphatase (ALP), blood urea nitrogen (BUN), total cholesterol (TC), and triglyceride (TG) were evaluated, which reflect liver and kidney functions. Compared with the normal saline treatment group, there were no differences in the values of biochemical markers of Gd@CDs treated groups (Table 1), suggesting no obvious hepatic or kidney disorder of mice induced by Gd@CDs treatment. From the histopathology of treated mice tissues, there were almost no apparent histopathological abnormalities or lesions observed in the heart, kidney, liver, and spleen, compared with the control groups (Additional file 1: Figure S7). However, the H\&E staining images of the lung tissues revealed the presence of peribronchial and perivascular cellular infiltrates at $0.3 \mathrm{mg} / \mathrm{kg}$ and $3 \mathrm{mg} / \mathrm{kg}$ dosages, which indicated that Gd@CDs evoked moderate lung inflammatory responses (Additional file 1: Figure S7). Similar phenomena were also observed in the other carbonaceous nanomaterials, such as polyaminebased CDs [41], carboxylated CDs [42] and carbon nanotubes $[43,44]$. Since the lung hosted multiple populations of macrophages, Gd@CDs may alter the steady state of oxidative stress induced by excessive generation of reactive oxygen species and depletion of antioxidants levels, causing production of proinflammatory cytokines in lung cells $[41,45,46]$. Necrosis was not found in histological samples. Above all, Gd@CDs exhibited good biocompatibility in vivo. Therefore, Gd@CDs were suitable for further application in biomaterials.

\section{Preparation and the properties of Dox@IR825@Gd@CDs}

Photothermal agent IR825 and anti-tumor drug Dox were loaded on the surface of Gd@CDs. The as-synthesized Dox@IR825@Gd@CDs can be purified by filtration to remove free Dox and IR825. As shown Fig. 3a, a strong absorption peak in the range of $700-850 \mathrm{~nm}$ was observed, ascribing to the successful loading of IR825. The two typical peaks observed at $253 \mathrm{~nm}$ and $290 \mathrm{~nm}$ and the increased absorbance in the range of $470-550 \mathrm{~nm}$ proved that Dox had been loaded on the Gd@CDs. The loading efficiencies of Dox and IR825 were quantified to be 16.4\% and 8.9\% in Dox@IR825@Gd@CDs, respectively. Moreover, the drug encapsulation efficiencies of Dox and IR825 were quantified to be $68.8 \%$ and $83.3 \%$, respectively. The zeta potentials of Dox and IR825 were $6.37 \pm 2.5 \mathrm{mV}$ and $3.68 \pm 1.9 \mathrm{mV}$, while the surface charge of Gd@CDs was negative charge, a zeta potential was $-16.7 \pm 2.8 \mathrm{mV}$. Therefore, Dox and IR825 were absorbed on the carbon dots owing to electrostatic interactions. The FI-IR and XPS results strongly suggested that Gd@CDs were functionalized with various groups, such as hydroxyl groups, amide groups and carboxylic acid groups. Hence, the hydrogen bonds may be formed between Gd@CDs and drugs (Dox and IR825) as well as

Table 1. Blood biochemistry analysis of mice after injection of saline (control group) or Gd@CDs (0.3 mg/kg and $3 \mathrm{mg} / \mathrm{kg}$ weight) for 16 days $(x \pm s)$

\begin{tabular}{|c|c|c|c|c|}
\hline biochemical markers & Control group & $\begin{array}{l}\mathrm{Gd@CDs} \\
0.3 \mathrm{mg} / \mathrm{kg}\end{array}$ & $\begin{array}{l}\text { Gd@CDs } \\
3 \mathrm{mg} / \mathrm{kg}\end{array}$ & $P$ \\
\hline $\mathrm{TP}(\mathrm{g} / \mathrm{L})$ & $63.62 \pm 4.91$ & $64.48 \pm 8.64$ & $63.77 \pm 3.08$ & 0.96 \\
\hline ALT (U/L) & $50.00 \pm 12.55$ & $56.58 \pm 15.84$ & $55.03 \pm 15.95$ & 0.73 \\
\hline AST (U/L) & $230.42 \pm 88.46$ & $267.65 \pm 75.51$ & $244.10 \pm 104.89$ & 0.77 \\
\hline $\mathrm{ALP}(\mathrm{U} / \mathrm{L})$ & $193.48 \pm 78.97$ & $177.00 \pm 44.67$ & $178.70 \pm 49.63$ & 0.87 \\
\hline BUN (mmol/L) & $10.46 \pm 2.02$ & $9.83 \pm 1.56$ & $8.62 \pm 2.75$ & 0.35 \\
\hline $\mathrm{TC}(\mathrm{mmol} / \mathrm{L})$ & $2.32 \pm 0.56$ & $2.14 \pm 0.56$ & $2.32 \pm 0.34$ & 0.78 \\
\hline $\mathrm{TG}(\mathrm{mmol} / \mathrm{L})$ & $1.54 \pm 0.69$ & $1.60 \pm 0.50$ & $1.25 \pm 0.27$ & 0.47 \\
\hline
\end{tabular}

TP Total protein, ALT alanine aminotransferase, AST aspartate aminotransferase, ALP alkaline phosphatase, BUN blood urea nitrogen, TC total cholesterol, TG triglyceride 

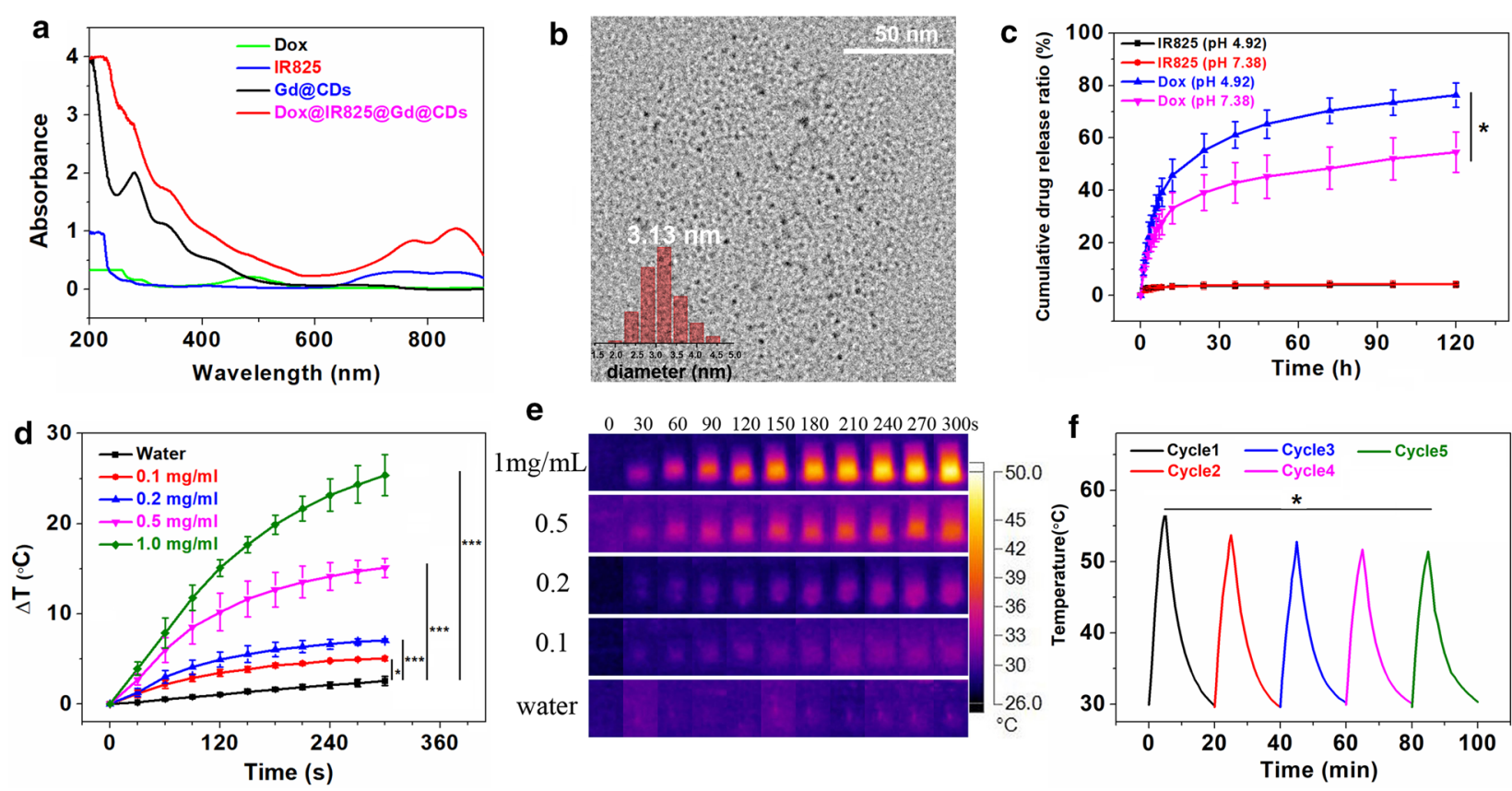

Fig. 3 a The absorbance spectra of Gd@CDs before and after loading Dox and IR825; b HRTEM imaging of Dox@IR825@Gd@CDs (inset, statistical analysis by nanomeasurer software); $\mathbf{c}$ Dox and IR825 release curves at different $\mathrm{pH}(\mathrm{pH}=4.92,7.38)$; $\mathbf{d}$ Temperature curves of deionized water and Dox@IR825@Gd@CDs solutions at different concentrations during NIR laser irradiation (808 nm, 3 W); e The IR thermal images of deionized water and Dox@IR825@Gd@CDs solution (1 mg/mL) after NIR laser irradiation (808 nm,3W);f Temperature increments of Dox@IR825@Gd@CDs $(1 \mathrm{mg} / \mathrm{mL})$ suspension under NIR laser irradiation $\left(808 \mathrm{~nm}, 3 \mathrm{~W}\right.$ ) for five cycles ( 5 min for each cycle). Data expressed as mean $\pm S D, n=3 .{ }^{*} P<0.05$; ${ }^{* *} P<0.01 ; * * * 0.005$. $P$ values represent the outcome of Multiple Comparisons in Analysis of Variance (ANOVA)

electrostatic interactions. The average diameter of Dox@ IR825@Gd@CDs increased to 3.13 nm after loading Dox and IR825 (Fig. 3b) as a result of the increased amount of Dox and IR825. The stability of Dox@IR825@Gd@CDs in PBS with 10\% FBS was investigated in vitro based on the DLS assays. The average hydrodynamic diameters were in the range from $228.8 \pm 7.8 \mathrm{~nm}$ to $205.2 \pm 9.8 \mathrm{~nm}$, suggesting that the size was slightly decreased in $99 \mathrm{~h}$, which showed that Dox@IR825@Gd@CDs were stable in physiological-mimicking environment (Additional file 1: Figure S8).

The release amount of IR825 reached $4.2 \%$ at $\mathrm{pH} 7.38$ and $4.1 \%$ at pH 4.92 after 120 h (Fig. 3c). After statistical analysis, there was no difference between the release amount of IR825 at $\mathrm{pH} 7.38$ and $\mathrm{pH} 4.92$ after $120 \mathrm{~h}$ $(P=0.902)$. However, the release of Dox was significantly boosted on the acidic condition. 76.4\% of Dox was released at $\mathrm{pH} 4.92$, while only $55.6 \%$ of Dox was released at $\mathrm{pH} 7.38(P=0.014)$, which may be due to the protonation of amine groups on Dox under the acidic conditions. The release ratio of IR825 remained constant under different $\mathrm{pH}$ conditions, while Dox had a better release in the weak acidic environment. Considering the intracellular microenvironment of cancer cells was slightly acidic in the endosomal and lysosomal compartments $[47,48]$, such carbon nanoplatform showed a great potential for the delivery of anticancer drug Dox to cancer cells. Additionally, low release ratio of IR825 had a benefit to exert a photothermal effect on the tumor site.

In order to investigate the photothermal effect, various concentrations of Dox@IR825@Gd@CDs solutions were illuminated by $808 \mathrm{~nm}$ NIR laser at $3 \mathrm{~W}$ for $5 \mathrm{~min}$ (Fig. 3d, e). Nonobvious temperature fluctuations were observed in control (deionized water). By contrast, the rate of temperature elevation of Dox@IR825@Gd@CDs showed a typical concentration-dependent manner. The temperature of Dox@IR825@Gd@CDs at $0.1 \mathrm{mg} / \mathrm{mL}$ increased by $5.0{ }^{\circ} \mathrm{C}(P=0.024)$, while that increased by $25.4{ }^{\circ} \mathrm{C}$ at $1.0 \mathrm{mg} / \mathrm{mL}$ after irradiation $(P<0.005)$, compared with the control. The thermal stability was a key factor to determine therapeutic efficacy of thermal therapy.Dox@IR825@Gd@CDs were irradiated with808 nm laser for five on / off cycles to evaluate the light stability (Fig. 3f). The temperature of each cycles were recorded at $57,53.7,52.8,51.7$ and $51.4{ }^{\circ} \mathrm{C}$. The temperature of the fifth cycle decreased $5.6{ }^{\circ} \mathrm{C}$ than that of the first cycle 
$(P=0.022)$. Slight decrease of the thermal effect would also be acceptable. Thus, Dox@IR825@Gd@CDs exhibited moderate photostability and could be implemented as a photothermal heater for photothermal therapy.

\section{Combined photothermal chemotherapy for TNBC in vitro}

Cellular uptake assays. The $4 \mathrm{~T} 1$ cells were incubated with Dox@IR825@Gd@CDs for 4h, the characteristic red fluorescence of Dox mainly appeared in the cytosol of $4 \mathrm{~T} 1$ cells, while the blue fluorescence of DAPI was showed in cell nuclei, which suggested that Dox@IR825@Gd@CDs easily entered 4T1 cells (Additional file 1: Figure S9).

Viability assays. Encouraged by the above results, the TNBC cells killing efficiency of Dox@IR825@Gd@CDs was evaluated in vitro. The cytotoxicity of Gd@CDs was also investigated against 4T1 cells and MDA-MB-231 cells by CCK- 8 assay (Fig. 4a, b). When the concentration of Gd@CDs increased to $1 \mathrm{mg} / \mathrm{mL}$ after $12 \mathrm{~h}$ incubation, 4T1 cells viability was still above 95\%, while MDAMB-231 cells viability was $75 \%$. The results indicated the lower cytotoxicity and better bio-safety of Gd@CDs for anticancer therapy.
In vitro anticancer study revealed a concentrationdependent viability of Dox@IR825@Gd@CDs (Fig. 4a). For the treatment of 4T1 cells, it was shown that the chemotherapeutic efficacy of the Dox@IR825@Gd@CDs without irradiation was lower than single photothermal efficacy of IR825@Gd@CDs under NIR irradiation at $0.2 \mathrm{mg} / \mathrm{mL}(P=0.002)$. The cellular viability of $4 \mathrm{~T} 1$ with Dox@IR825@Gd@CDs under NIR irradiation (combined treatment groups) were decrease to $26 \%$, compared with single photothermal group $(P=0.01)$. The time/pHdependent drug release characteristics of Dox@IR825@ Gd@CDs may lead to delayed therapeutic effects, thereby reducing cytotoxicity. Moreover, the anticancer efficacy of Dox@IR825@Gd@CDs drastically enhanced upon NIR irradiation for $5 \mathrm{~min}$, and cancer cells were almost completely destroyed at high concentrations. When the concentration of Dox@IR825@Gd@CDs was 0.5 mg/ $\mathrm{mL}$, over $97 \%$ cells in the combined treatment groups were died compared to single chemotherapy $(P=0.003)$ or single phototherapy groups $(P=0.235)$. Note that hypoxia was often generated upon the growth of solid tumor, resulting in poor antitumor efficacy [49]. Photothermal effect could overcome the resistance caused by


Control

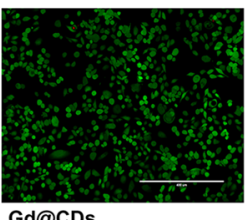

Gd@CDs
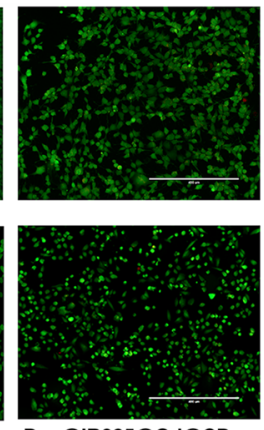

Dox@IR825@Gd@CDs
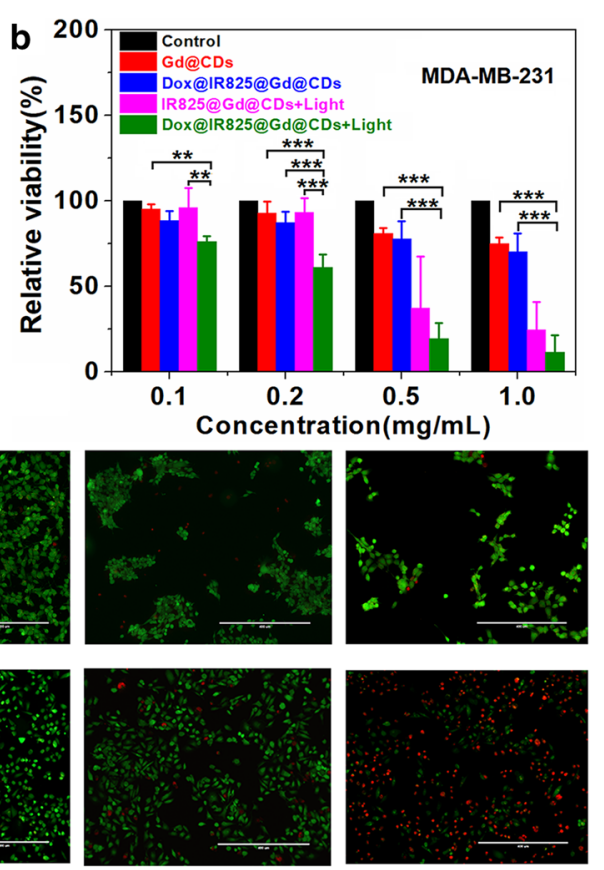

Fig. 4 The cellular viability of $4 \mathrm{~T} 1$ cells $\mathbf{a}$ and MDA-MB-231 cells $\mathbf{b}$ after various treatment; fluorescence images of the 4T1 cells $\mathbf{c}$ and MDA-MB-231 cells $\mathbf{d}$ stained with calcein-AM and PI after each treatment. Data expressed as mean $\pm \mathrm{SD}, \mathrm{n}=3,{ }^{*} P<0.05 ;{ }^{* *} P<0.01{ }^{* * *} P<0.005$. $P$ values represent the outcome of Multiple Comparisons in Analysis of Variance (ANOVA) 
hypoxia [50]. Hence, Dox@IR825@Gd@CDs under irradiation greatly inhibited $4 \mathrm{~T} 1$ cellular viability by combined photothermal chemotherapy. Interestingly, higher efficacy of Dox@IR825@Gd@CDs under irradiation was also observed in the treatment of MDA-MB-231 cells (Fig. 4b).

In order to visualize therapeutic efficiency combined photothermal chemotherapy treatment, the $4 \mathrm{~T} 1$ cells and MDA-MB-231 cells were co-stained by calcein AM and PI to evaluate live and dead cells (Fig. 4c, d). 4T1 cells and MDA-MB-231 cells in the chemotherapeutic treatment groups (Dox@IR825@Gd@CDs without irradiation) had slightly decreased compared with the control groups. The live 4T1 cells and MDA-MB-231 cells treated with IR825@Gd@CDs under NIR irradiation had further decreased. Notably, 4T1 cells and MDA-MB-231 cells in the combinational therapy groups (Dox@IR825@Gd@ CDs with NIR irradiation) showed a dramatic decrease in the number of live cells (green color). Taken together, these results demonstrated higher anticancer therapeutic efficiency of Dox@IR825@Gd@CDs when combined with PTT and chemotherapy.

\section{$M R I$ in vitro and in vivo}

Gd@CDs as $\mathrm{T}_{1}$ contrast agent improved the MRI effect by enhancing the longitudinal relaxation rate of surrounding water molecules. The brighter MRI was observed with increasing concentration of Gd@CDs (Fig. 5a). Under the same Gd dose, the MRI of Gd@CDs was brighter and clearer than that of Gd-DTPA, the commercial $\mathrm{T}_{1}$ MRI contrast agent, and the contrast effect was better than that of Gd-DTPA. According to Gd concentration and longitudinal relaxation rate $\mathrm{R} 1\left(1 / \mathrm{T}_{1}\right)$, the linear equations of Gd@CDs and Gd-DTPA were obtained by fitting (Fig. 5b). Compared with the longitudinal relaxation rate R1 of Gd-DTPA, Gd@CDs showed a 6.53-fold higher R1. This may due to the coordination between Gd and phenolic hydroxyl groups, which prolonged the molecular rotation related time, improved the relaxation rate of Gd@CDs, and significantly increased the intensity of MRI contrast signals.

The Dox@IR825@Gd@CDs aggregation and distribution were determined by MRI in vivo. As shown in Fig. 5c, the MR signals of Dox@IR825@Gd@CDs at tumor regions increased gradually with time following intravenous injection, reaching a maximum level at 4 h-post-injection. Additionally, the MR signals of Dox@ IR825@Gd@CDs were showed after10 min post injection in situ (Fig. 5d), indicating that the MR images were much vaguer through intravenous injection than those via injection in situ. This may be due to small sizes of Dox@IR825@Gd@CDs, resulting facile and fast excretion. It was not an ideal approach by tail vein injection to enrich Gd dose in the tumor area. However, intratumoral injection was an easier and more time-saving strategy to endow tumors with the enrichment of Gd@CDs.

\section{Combined photothermal chemotherapy for TNBC in vivo} Inspired by the features of the Dox@IR825@Gd@CDs, we further evaluated combined therapeutic efficacy in vivo. Female nude mice bearing $4 \mathrm{~T} 1$ tumors were chosen and randomly divided into four groups. The mice

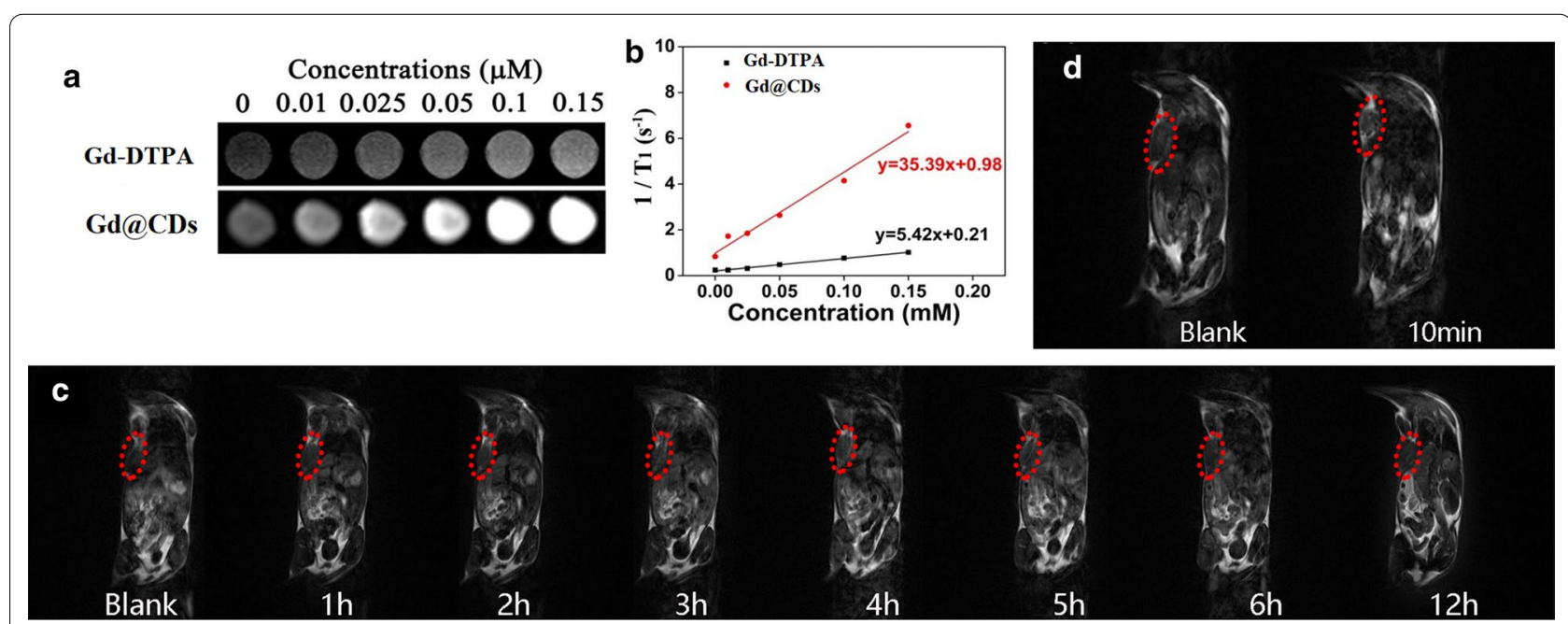

Fig. 5 a In vitro MRI of Gd-DTPA and Gd@CDs; b Linear fit between Gd ${ }^{3+}$ concentration and relaxation rate; c In vivo MRI before and after intravenous injection Dox@IR825@Gd@CDs solution.d In vivo MRI of mice before and after intratumoral injection of Dox@IR825@Gd@CDs solution 

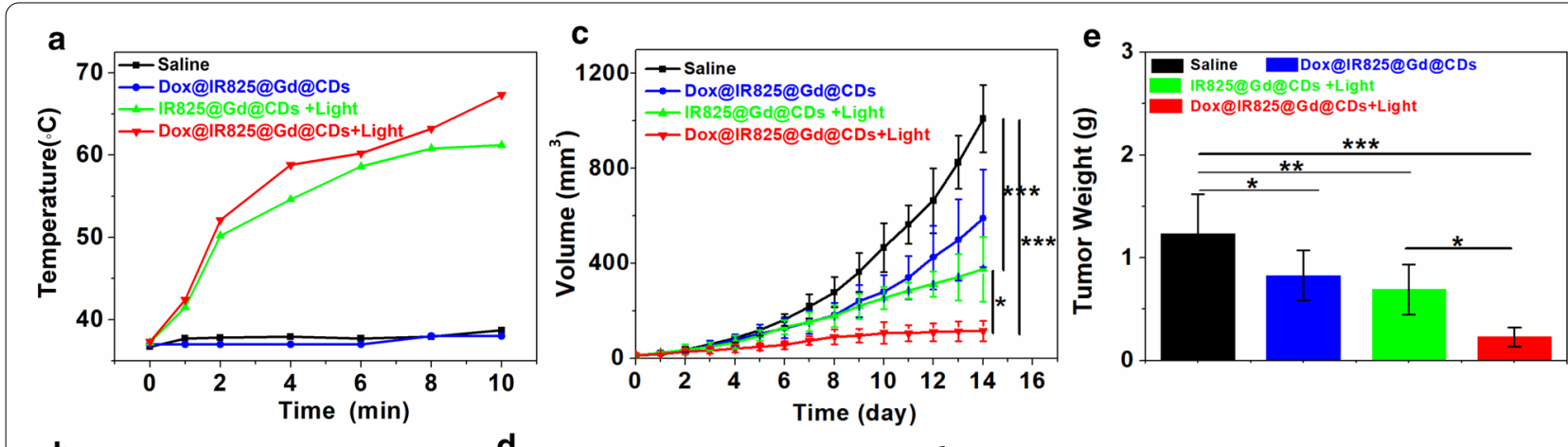

$$
\text { b } 0
$$

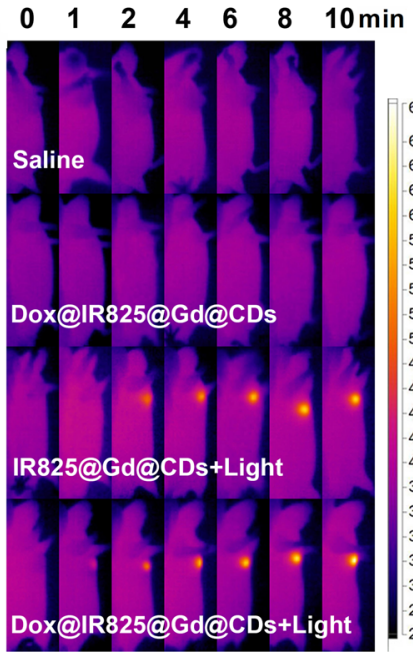

$\begin{array}{llllllll}d & 0 & 2 & 4 & 6 & 8 & 10 & 14 \\ & \text { Days } & f\end{array}$


IR825@Gd@CDs+Light

Dox@IR825@Gd@CDs+Light

h



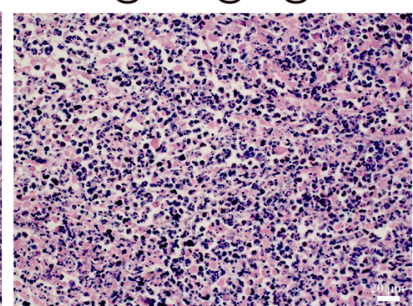

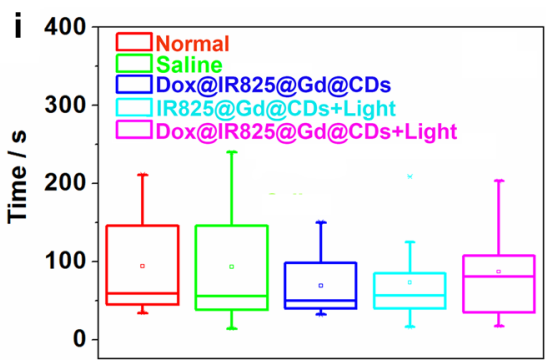




Fig. 6 In vivo antitumor efficiency of different treatments: (1) saline ( $n=5),(2)$ Dox@IR825@Gd@CDs ( $n=5)$, (3) IR825@Gd@CDs+808 nm irradiation (1.5W, n=5), (4) Dox@IR825@Gd@CDs+808 nm irradiation (1.5 W, n=5): a Temperature curves of 4T1 tumor-bearing mice after treatment. b Thermographic images of 4T1 tumor-bearing mice after treatment. c Tumor volume change curves. $\mathbf{d}$ Photographs of 4T1 tumor-bearing mice during different treatments. e Tumor weight collected from mice after 14 days treatments. f Photographs of tumor tissues collected from mice after 14 days treatments. $\mathbf{g}$ H\&E-stained images of tumor slices. $\mathbf{h}$ Body weight changes. $\mathbf{i}$ Comparison of mice rotarod test performance between various treatments. j Drug biodistribution of 4T1 tumor-bearing mice following injection of Dox@IR825@Gd@CDs.*P<0.05; ${ }^{* *} P<0.01 ;{ }^{* *} P<0.005$. $P$ values represent the outcome of Multiple Comparisons in Analysis of Variance (ANOVA) 
were intratumorally injected and the time-dependent temperature changes on the surface of tumor site were monitored using a thermal imager (Fig. 6a, b). The temperatures were rapidly increased under irradiation in IR825@Gd@CDs and Dox@IR825@Gd@CDs groups. The tumor tissue would suffer irreversible damage owe to the continued high temperature. The tumor volume of each mouse were measured every day during the treatment (Fig. 6c). As compared with the saline injected group, the tumors treated with chemotherapy alone (Dox@IR825@Gd@CDs without NIR irradiation) and photothermal therapy alone (IR825@Gd@CDs with NIR irradiation) grew slowly, but the tumor growth was only partially suppressed (Fig. 6c-f). By contrast, the mice treated with Dox@IR825@Gd@CDs under NIR irradiation exhibited the best tumor growth inhibition due to synergistic photothermal chemotherapeutic efficiency. The weights and sizes of isolated tumors after the combination therapy were the smallest in all the treated groups (Fig. 6e, f), showing excellent tumor inhibition efficacy of the combination therapy. In chemotherapy alone or photothermal therapy alone groups, tumor slices showed some tumor tissue necrosis (Fig. $6 \mathrm{~g}$ ). The shrinking and fragmented tumor cell nuclei were found and large numbers of granulocytes were dead. Moreover, tumor slices displayed that Dox@IR825@Gd@CDs under NIR irradiation killed more TNBC tumor cells thoroughly after synergistic photothermal chemotherapy (Fig. 6g). The body weight loss can be used as an indicator to evaluate the side effects of the treatment. Negligible differences in the body weights were observed in all treatment groups $(P=0.272$, Fig. 6 h). Mice rotarod test can be used for evaluation of murine motor coordination and the side effects of the treatment [51]. Based on mice rotarod test performance in various treated groups (Fig. 6i), there were no statistically significant difference for the average duration between the normal groups and experiment groups. Biodistribution of Dox@IR825@Gd@CDs in 4T1-tumor-bearing mice at $24 \mathrm{~h}$ post-inject was studied by measuring Gd levels in various organs using ICP-MS (Fig.6j).Dox@IR825@Gd@CDs showed a rather high tumor accumulation at $5.4 \%$ of injected dose per gram tissue (ID/g), kidney accumulation at $0.6 \% \mathrm{ID} / \mathrm{g}$. Furthermore, pathological morphological analysis was performed on the main organs of each treatment group to evaluate the systemic toxicity. Compared with the saline treatment groups, slices of the major organs showed no noticeable organ damages or inflammatory lesion (Additional file1: Figure S10). Thus, these results demonstrated that Dox@IR825@Gd@CDs with NIR irradiation efficiently inhibited tumor growth and enhanced the treatment efficacy after combined PPT and chemotherapy.

\section{Conclusions}

In summary, Gd@CDs were synthesized through a facile hydrothermal method, that emitted blue fluorescence and exhibited excellent biocompatibility. Taking advantage of Gd@CDs, a noble theranostic nanoplatform (Dox@IR825@Gd@CDs) was developed that could be tailored to achieve loading of Dox and IR825, intracellular delivery, favorable MRI, excellent combination therapy with PTT and chemotherapy to enhance therapeutic effect against TNBC cells. Additionally, Dox@IR825@ Gd@CDs presented low toxicity during the treatment, which provided a potential and singular approach to treat TNBC.

\section{Supplementary Information}

The online version contains supplementary material available at https://doi. org/10.1186/s12951-021-00811-w.

Additional file 1. The experimental section of radical scavenging activity and hemolysis assay. Figure S1. Hydrodynamic diameter and fluorescence lifetime of Gd@CDs, and fluorescence intensity of Gd@CDs at different temperatures. Figure S2. The Influencing factors of fluorescence properties on Gd@CDs. Figure S3. Photobleaching characteristics and evaluation of free radical scavenging activity. Figure S4. Hemolysis experiment, and cellular viability of Gd@CDs with 293 T cells. Figure S5. H\&E stained sections of major organs at 24 h post injection of Gd@CDs. Figure S6. Body weight changes of mice during 16 days treatments. Figure S7. H\&E stained sections of major organs after 16 days treatments. Figure S8. Stability of Dox@|R825@Gd@CDs. Figure S9.The cellular uptake of Dox@ IR825@Gd@CDs by 4T1 cells. Figure S10. H\&E stained sections of major organs of $4 \mathrm{~T} 1$ tumor-bearing mice after 14 days treatments.

\section{Abbreviations}

TNBC: Triple negative breast cancer; Gd: Gadolinium; Gd@CDs: Gd-encapsulated carbon dots; Dox: Doxorubicin hydrochloride; NIR: Near-infrared; MRI: Magnetic resonance imaging; Gd-DTPA: Gadopentetate dimeglumine; Gd-DOTA: Gadolinium 1,4,7,10-tetraazacyclododecane-1,4,7,10-tetraacetic acid; NSF: Nephrogenic systemic fibrosis; CDs: Carbon dots; PTT: Photothermal therapy; DHCA: 3,4-Dihydroxyhydrocinnamic acid; EDA: 2,2'-(Ethylenedioxy) bis(ethylamine); $\mathrm{GdCl}_{3}$ : Anhydrous gadolinium chloride; DPPH: 1,1-Diphenyl2-picrylhydrazyl; FBS: Fetal bovine serum; CCK-8: Cell Counting Kit-8; NMR: Nuclear magnetic resonance; FT-IR: Fourier transform infrared; ICP-MS: Inductively coupled plasma mass; XPS: X-ray photoelectron spectroscopy; ANOVA: Analysis of variance; DLS: Dynamic light scattering; TP: Total protein; ALT: Alanine aminotransferase; AST: Aspartate aminotransferase; ALP: Alkaline phosphatase; BUN: Blood urea nitrogen; TC: Total cholesterol; TG: Triglyceride.

\section{Acknowledgements}

This study was supported by the Guangxi Universities Key Laboratory of Prevention and Control of Highly Prevalent Diseases, School of Public Health, Guangxi Medical University, and State Key Laboratory of Non-food Biomass and Enzyme Technology, Guangxi Academy of Sciences.

\section{Authors' contributions}

$\mathrm{GH}, \mathrm{XC}$ and RP designed the study, GH, XC and DH provided all the resources. QJ, LL and QL performed the experiments. YC, DC, and QD performed MRI. DH and $X Y$ provided methodology. $Q J, L L, X C$ and $G H$ wrote the manuscript. All authors read and approved the final manuscript.

\section{Funding}

This work was supported from Natural Science Foundation of Guangxi Province (2017GXNSFBA198028), Middle-aged and Young Teachers'Basic Ability 
Promotion Project of Guangxi (2018KY0100) and the National Natural Science Foundation of China (81960558).

\section{Availability of data and materials}

The data are available in the main manuscript, supplementary Information files, and from the corresponding authors upon reasonable request.

\section{Ethics approval and consent to participate}

All experiments were approved by the Ethics Committee of Guangxi Medical University and carried on in strict compliance with the relevant laws and institutional guidelines of Guangxi Medical University, Nanning, China (20140307A, 20140307B).

\section{Consent for publication}

All the authors have approved the manuscript and agree with submission to your esteemed journal.

\section{Competing interests}

The authors declare no competing financial interest.

Received: 9 November 2020 Accepted: 19 February 2021

Published online: 02 March 2021

\section{References}

1. Chen GY, Roy I, Yang CH, Prasad PN. Nanochemistry and nanomedicine for nanoparticle-based niagnostics and therapy. Chem Rev. 2016;116:2826-85.

2. Aftab S, Shah A, Nadhman A, Kurbanoglu S, Aysıl Ozkan S, Dionysiou DD, et al. Nanomedicine: an effective tool in cancer therapy. Int J Pharmaceutics. 2018;540(1):132-49.

3. Peer D, Karp JM, Hong S, FaroKhzad OC, Margalit R, Langer R. Nanocarriers as an emerging platform for cancer therapy. Nat Nanotech. 2007;2(12):751-60.

4. Cleary J, Guimarães AR. Magnetic Resonance Imaging. In: Pathobiology of Human Disease. edn. San Diego: Academic Press. 2014;3987-4004

5. Corradini S, Alongi F, Andratschke N, Belka C, Boldrini L, Cellini F, et al. MR-guidance in clinical reality: current treatment challenges and future perspectives. Radiat Oncol. 2019;14(1):92.

6. Terreno E, Castelli DD, Viale A, Aime S. Challenges for molecular magnetic resonance imaging. Chem Rev. 2010;110(5):3019-42.

7. Biagi BA, Enyeart JJ. Gadolinium blocks low- and high-threshold calcium currents in pituitary cells. Am J Physiol. 1990;259:C515-20.

8. Molgó J, del Pozo E, Baños JE, Angaut-Petit D. Changes of quantal transmitter release caused by gadolinium ions at the frog neuromuscular junction. Br J Pharmacol. 1991;104(1):133-8.

9. Idée JM, Port M, Raynal I, Schaefer M, Le Greneur S, Corot C. Clinical and biological consequences of transmetallation induced by contrast agents for magnetic resonance imaging: a review. Fundam Clin Pharmacol. 2006:20(6):563-76.

10. Le FM, Caravan P. The biological fate of gadolinium-based MRI contrast agents: a call to action for bioinorganic chemists. Metallomics. 2019;11(2):240-54.

11. Gao ZY, Ma TC, Zhao EY, Docter D, Yang WS, Stauber RH, et al. Small is smarter: mano MRI contrast agents - advantages and recent achievements. Small. 2016;12(5):556-76.

12. Patel KD, Singh RK, Kim HW. Carbon-based nanomaterials as an emerging platform for theranostics. Mater Horizons. 2019;6(3):434-69.

13. Jia QY, Zhao ZY, Liang K, Nan FC, Li Y, Wang J, et al. Recent advances and prospects of carbon dots in cancer nanotheranostics. Mater Chem Front. 2020;4(2):449-71.

14. Anders CK, Zagar TM, Carey LA. The management of early-stage and metastatic triple-negative breast cancer: a review. Hematol Oncol Clin North Am. 2013;27(4):737-49.

15. Trivers KF, Lund MJ, Porter PL, Liff JM, Flagg EW, Coates RJ, et al. The epidemiology of triple-negative breast cancer, including race. Cancer Causes Control. 2009:20(7):1071-82.
16. Cardoso F, Senkus E, Costa A, Papadopoulos E, Aapro M, André F, et al. 4th ESO-ESMO international consensus guidelines for advanced breast cancer (ABC 4). Ann Oncol. 2018;29(8):1634-57.

17. Gobbini E, Ezzalfani M, Dieras V, Bachelot T, Brain E, Debled M, et al. Time trends of overall survival among metastatic breast cancer patients in the real-life ESME cohort. Eur J Cancer. 2018;96:17-24.

18. Shao LH, Li Q, Zhao CY, Lu JQ, Li XL, Chen L, et al. Auto-fluorescent polymer nanotheranostics for self-monitoring of cancer therapy via triple-collaborative strategy. Biomaterials. 2019;194:105-16.

19. Wang TT, Wang DG, Yu HJ, Wang MW, Liu JP, Feng B, et al. IntracelIularly acid-switchable multifunctional micelles for combinational photo/chemotherapy of the drug-resistant tumor. ACS Nano. 2016;10(3):3496-508.

20. Nam J, Son SJ, Ochyl LJ, Kuai R, Schwendeman A, Moon JJ. Chemophotothermal therapy combination elicits anti-tumor immunity against advanced metastatic cancer. Nat Commun. 2018;9(1):1074.

21. Shi JJ, Kantoff PW, Wooster R, Farokhzad OC. Cancer nanomedicine: progress, challenges and opportunities. Nat Rev Cancer. 2017; 17(1):20-37.

22. Chen F, Cai WB. Nanomedicine for targeted photothermal cancer therapy: where are we now? Nanomedicine. 2015;10(1):1-3.

23. Fay BL, Melamed JR, Day ES. Nanoshell-mediated photothermal therapy can enhance chemotherapy in inflammatory breast cancer cells. Int J Nanomedine. 2015;10:6931-41.

24. Jin J, Guo MY, Liu JM, Liu J, Zhou HG, Li JY, et al. Graphdiyne nanosheetbased drug delivery platform for photothermal/chemotherapy combination treatment of cancer. ACS Appl Mater Interfaces. 2018;10(10):8436-42.

25. Li Y, Lin JY, Wang PY, Luo Q, Lin HR, Zhang Y, et al. Tumor microenvironment responsive shape-reversal self-targeting virus-Inspired nanodrug for imaging-guided near-infrared-II photothermal chemotherapy. ACS Nano. 2019:13(11):12912-28.

26. Gao D, Guo X, Zhang X, Chen S, Wang Y, Chen T, et al. Multifunctional phototheranostic nanomedicine for cancer imaging and treatment. Materials Today Bio. 2020;5:100035.

27. Qu KG, Wang JS, Ren JS, Qu XG. Carbon dots prepared by hydrothermal treatment of dopamine as an effective fluorescent sensing platform for the label-free detection of iron(III) ions and dopamine. Chem Eur J. 2013;19(22):7243-9.

28. Arcudi F, Đorđević L, Prato M. Rationally designed carbon nanodots towards pure white-light emission. Angew Chem Int Ed 2017;56(15):4170-3

29. Chen H, Wang LN, Fu H, Wang ZY, Xie YJ, Zhang ZJ, et al. Gadolinium functionalized carbon dots for fluorescence/magnetic resonance dual-modality imaging of mesenchymal stem cells. J Mater Chem B. 2016;4(46):7472-80.

30. Miao X, Yan XL, Qu D, Li DB, Tao FF, Sun ZC. Red Emissive sulfur, nitrogen codoped carbon dots and their application in ion detection and theraonostics. ACS Appl Mater Interfaces. 2017;9(22):18549-56.

31. Li LP, Lu CX, Li SJ, Liu SJ, Wang LJ, Cai WW, et al. A high-yield and versatile method for the synthesis of carbon dots for bioimaging applications. J Mater Chem B. 2017:5(10):1935-42.

32. Sapkota B, Benabbas A, Lin H-YG, Liang WT, Champion P, Wanunu M. Peptide-decorated tunable-fluorescence graphene quantum dots. ACS Appl Mater Interfaces. 2017;9(11):9378-87.

33. Xu Y, Jia XH, Yin XB, He XW, Zhang YK. Carbon Quantum Dot Stabilized Gadolinium Nanoprobe prepared via a one-pot hydrothermal approach for magnetic resonance and fluorescence dual-modality bioimaging. Anal Chem. 2014;86(24):12122-9.

34. Gong NQ, Wang H, Li S, Deng YL, Chen XA, Ye L, et al. Microwave-assisted polyol synthesis of gadolinium-doped green luminescent carbon dots as a bimodal nanoprobe. Langmuir. 2014;30(36):10933-9.

35. Shi BF, Su YB, Zhang LL, Liu RJ, Huang MJ, Zhao SL. Nitrogen-rich functional groups carbon nanoparticles based fluorescent $\mathrm{pH}$ sensor with broad-range responding for environmental and live cells applications. Biosens Bioelectron. 2016;82:233-9.

36. Gao ZF, Li TT, Xu XL, Liu YY, Luo HQ, Li NB. Green light-emitting polyepinephrine-based fluorescent organic dots and its application in intracellular metal ions sensing. Biosens Bioelectron. 2016;83:134-41. 
37. Chen HM, Wang GD, Sun XL, Todd T, Zhang F, Xie J, et al. Mesoporous silica as nanoreactors to prepare Gd-encapsulated carbon dots of controllable sizes and magnetic properties. Adv Funct Mater. 2016;26(22):3973-82.

38. Wang WJ, Hai X, Mao QX, Chen ML, Wang JH. Polyhedral oligomeric silsesquioxane functionalized carbon dots for cell imaging. ACS Appl Mater Interfaces. 2015;7(30):16609-16.

39. Chen $X X$, Jin QQ, Wu LZ, Tung $C H$, Tang XJ. Synthesis and unique photoluminescence properties of nitrogen-rich quantum dots and their applications. Angew Chem. 2014;126:12750-5.

40. Wang CC, Huang PT, Shang KH, Wu SM. Cu ${ }^{2+}$-induced quenching and recovery of the luminescence of dopamine-conjugated carbon dots for sensing deferasirox in plasma. Sensors Actuators B. 2020;311:127916.

41. Weiss M, Fan J, Claudel M, Lebeau L, Pons F, Ronzani C. Combined in vitro and in vivo approaches to propose a putative adverse outcome pathway for acute lung inflammation induced by nanoparticles: a study on carbon dots. Nanomaterials. 2021;11(1):180.

42. Nurunnabi M, Khatun Z, Huh KM, Park SY, Lee DY, Cho KJ, et al. In vivo biodistribution and toxicology of carboxylated graphene quantum dots. ACS Nano. 2013;7(8):6858-67.

43. Ronzani C, Spiegelhalter C, Vonesch JL, Lebeau L, Pons F. Lung deposition and toxicological responses evoked by multi-walled carbon nanotubes dispersed in a synthetic lung surfactant in the mouse. Arch Toxicol. 2012;86(1):137-49.

44. Shvedova AA, Kisin ER, Mercer R, Murray AR, Johnson VJ, Potapovich Al, et al. Unusual inflammatory and fibrogenic pulmonary responses to singlewalled carbon nanotubes in mice. Am J Physiol Lung Cell Mol Physiol. 2005;289(5):L698-708.

45. Nho R. Pathological effects of nano-sized particles on the respiratory system. Nanomedicine. 2020;29:102242.
46. Mishra A, Stueckle TA, Mercer RR, Derk R, Rojanasakul Y, Castranova V, et al. Identification of TGF- $\beta$ receptor- 1 as a key regulator of carbon nanotube-induced fibrogenesis. Am J Phys Lung Cell Molecular Phys. 2015;309(8):L821-33.

47. Choi CA, Lee JE, Mazrad ZAI, Kim YK, In I, Jeong JH, et al. Dual-responsive carbon dot for $\mathrm{pH} /$ redox-triggered fluorescence imaging with controllable photothermal ablation therapy of cancer. ChemMedChem. 2018;13(14):1459-68.

48. Zhang YY, Ang CY, Li MH, Tan SY, Qu QY, Zhao YL. Polymeric prodrug grafted hollow mesoporous silica nanoparticles encapsulating near-infrared absorbing dye for potent combined photothermal-chemotherapy. ACS Appl Mater Interfaces. 2016;8(11):6869-79.

49. Wilson WR, Hay MP. Targeting hypoxia in cancer therapy. Nat Rev Cancer. 2011;11(6):393-410.

50. Zhang YY, Yang D, Chen HZ, Lim WQ, Phua FSZ, An GH, et al. Reduction-sensitive fluorescence enhanced polymeric prodrug nanoparticles for combinational photothermal-chemotherapy. Biomaterials. 2018;163:14-24.

51. Shiotsuki H, Yoshimi K, Shimo Y, Funayama M, Takamatsu Y, Ikeda K, et al. A rotarod test for evaluation of motor skill learning. J Neurosci Methods. 2010;189(2):180-5.

\section{Publisher's Note}

Springer Nature remains neutral with regard to jurisdictional claims in published maps and institutional affiliations.
Ready to submit your research? Choose BMC and benefit from:

- fast, convenient online submission

- thorough peer review by experienced researchers in your field

- rapid publication on acceptance

- support for research data, including large and complex data types

- gold Open Access which fosters wider collaboration and increased citations

- maximum visibility for your research: over 100M website views per year

At BMC, research is always in progress.

Learn more biomedcentral.com/submissions 